Microwave synthesis of functionally graded tricalcium phosphate for osteoconduction

$$
\text { by }
$$

Donya Thomas, B.S.

A Thesis

In

\title{
Bioengineering
}

Submitted to the Graduate Faculty

ofTexasTechUniversity in

Partial Fulfillment of

the Requirements for

the Degree of

\section{MASTER OF SCIENCES}

Approved

Dr. Michelle Pantoya

Chair of Committee

Dr. Stephen Ekwaro-Osire

Dr. Jingling Qiu

Mark Sheridan

Dean of the Graduate School

May, 2016 
Copyright 2016, DonyaThomas 


\section{ACKNOWLEDGMENTS}

I would like to thank Dr. Michelle Pantoya for her continuous encouragement and guidance throughout the entire research process. I would like to thank the thesis committee for their guidance and feedback. This thesis would also not have been made possible with the support and help from my colleagues in the Combustion Lab. 


\section{TABLE OF CONTENTS}

ACKNOWLEDGMENTS .................................................................................. ii

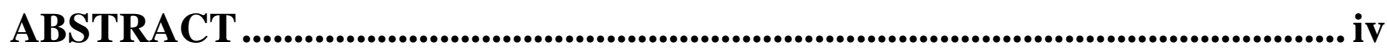

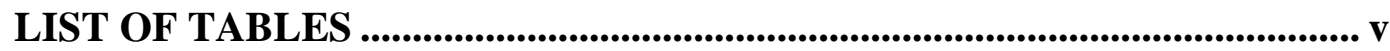

LIST OF FIGURES ...................................................................................................... vi

I. INTRODUCTION .............................................................................................................. 1

II. MATERIALS AND METHODS .......................................................................... 4

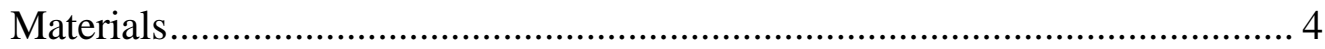

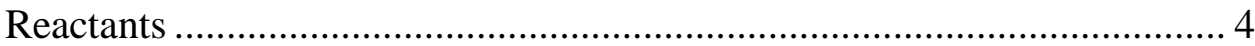

Mixture-sample preparation ................................................................ 4

Microwave combustion synthesis …………………….............................. 5

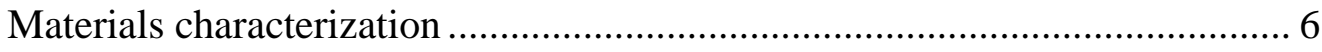

III. RESULTS AND DISCUSSION.............................................................................. 7

Microwave combustion synthesis ………………………………………... 7

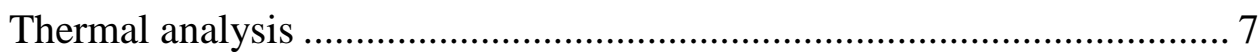

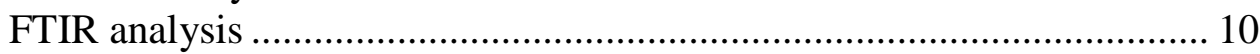

Semi-infinite solid ........................................................................ 12

Lumped capacitance (volumetric) .......................................................... 14

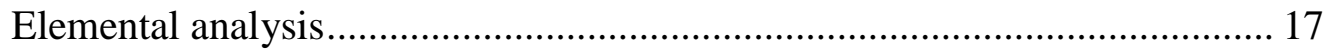

Functionally graded porosity.................................................................... 19

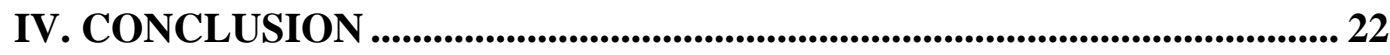

BIBLIOGRAPHY ................................................................................................. 23 


\begin{abstract}
Porosity is an important parameter of biomaterials used to replace bone. Tricalcium phosphate (TCP) is a common ceramic used to substitute bone in small quantities and coat medical devices. Various urea to calcium phosphate concentration ratios $(\phi=1,1.5,2.5)$ were used to analyze the effects of microwave irradiation on final product porosity. Results show heating in two phases: initially thermal energy is localized along the surface of the sample followed by volumetric heating. The product material is confirmed to be tricalcium phosphate via FTIR analysis. Scanning electron microscopy (SEM) images show increased porosity with increased urea concentration. A new method was then used to develop functionally graded porosity throughout a TCP bone cement structured that varied by controlling stoichiometry (i.e., $\phi$ varied from 1 to 2.5). This study provides a new perspective on volumetric combustion synthesis by using weak microwave energy to facilitate the formation of a tailored TCP structure.
\end{abstract}




\section{LIST OF TABLES}

3.1 EDS illustrates the highest weight percent of the product is composed of oxygen, phosphorus, and calcium......................... 18

3.2 Porosity analysis from ImageJ shows the increase in mean pore size as a result of increased urea concentration dissertations as indicated by the 3 equivalence ratios evaluated 


\section{LIST OF FIGURES}

2.1 Schematic shows the IR camera capturing images of the sample to be analyzed on the FLIR ResearchIR software as a result of the electromagnetic wave in the WR430 waveguide

3.1 Average temperature change of material heated at $2.6 \mathrm{GHz}(140$

W) shows two different temperature trends as the reactant goes from semi-infinite solid to volumetric heating

3.2 Graphical output shows the electromagnetic wave at (a) 29 seconds (b) and 59 seconds in the WR430 waveguide 8

3.3 Average temperature change of material heted at $2.45 \mathrm{GHz}$ at 3 different equivalence ratios shows a more linear temperature gradient at $\phi=2.5$

3.4 Transmittance as a function of wavenumber from FTIR analysis shows product species is tricalcium phosphate for sample heated at $2.45 \mathrm{GHz}$. Equivalence ratio of form indicated for each curve

3.5 Transmittance as a function of wavenumber from FTIR analysis shows product species is tricalcium phosphate for sample heated at $2.6 \mathrm{GHz}$

3.6 Graphical output during the first 30 seconds of microwave synthesis shows semi-infinite solid thermal behavior

3.7 Graphical output after 30 seconds of microwave heating shows volumetric heating

3.8 Energy Dispersive Spectrometry (EDS) illustrates the reulting product species is tricalcium phosphate.

3.9 Scanning Electron Microscopy micrographs with varied resolution as indicated for 3 different equivalence ratios, (a) $\phi=2.5$, (b) $\phi=1.5$, (c) $\phi=1$, indicating increasing pore structure with increasing equivalence ratio.

3.10 Scanning Electron Microscopy micrographs at as indicated for 3 different equivalence ratios, (a) $\phi=1$, (b) $\phi=1 / 2.5$ (mixed), (c) $\phi=2.5$, indicating increasing pore structure with increasing equivalence ratio. 


\section{CHAPTER I INTRODUCTION}

There is an increasing demand for medical devices and therapies due to the increase in the aging population. Some biomedical applications that affect this aging population are orthopedic implants such as knee and hip replacements. Any device that is to be inserted in the body should have characteristics similar to the part of the body it is meant to augment or repair. Considerations include biocompatibility, porosity, strength, plasticity, and many others [1]. Orthopedic implants are often required to replace parts of the body that provide structure. Therefore, the use of knee and hip implants requires materials with load bearing properties. Metallic alloys are often used because they have high strength and resistance to fatigue [2]. However, metals can be subject to various types of corrosion once exposed to the aqueous environment of the body [2]. Bioceramics do not elicit negative responses from the body but cannot be used for load bearing applications because of its brittle nature. Using bioceramics as coatings for metallic alloys can provide a strong, long-lasting structure.

Tricalcium phosphate, TCP, is one of the most commonly used bioceramics [3]. It is corrosion resistant, bioresorbable, and bioactive [2]. Its resorbability and bioactivity are especially useful for osteoconduction and osteoinduction which stimulate bone growth on the surface of a material. Not only does TCP resemble bone, which is partly made up of calcium phosphate minerals [3], but it provides a tissuebiomaterial interaction that enables fixation for the implant and encourages new bone 
to grow as the biomaterial safely degrades over time [4]. This makes TCP a useful bone cement for medical device coatings and spine defect fillings.

One limitation of commercial TCP bone cements is porosity. Bone is composed of cancellous and cortical bone which are spongy and compact, respectively. Therefore, a truly biocompatible biomaterial would have the same structure. Thesepores can encourage and guide bone growth [3].

Combustion synthesis methods have been explored for TCP bone cement. Vollmer et al. [5] and Volkmer et al. [6] mixed tricalcium phosphate with a fuel (urea, glycine) to alter the porosity of the final product. They then used self-propagating combustion and put this solution in a furnace at high temperatures. This resulted in a multiphasic TCP in which $\alpha$-TCP dissolves more readily than $\beta$-TCP in body fluids $[3,5,6]$. This resulted in non-uniform porosity and porosity along the grains caused by the wave propagation. [7].

Microwave synthesis has been proven as a valid technique for understanding the $\mathrm{pH}$ and ionic concentration effects of $\mathrm{KCl}, \mathrm{NaCl}, \mathrm{NaHCO}_{3}, \mathrm{MgCl}_{2} .2 \mathrm{H}_{2} \mathrm{O}, \mathrm{Na}_{2} \mathrm{SO}_{4}$, $\mathrm{CaCl}_{2} .2 \mathrm{H}_{2} \mathrm{O}$, and $\mathrm{KH}_{2} \mathrm{PO}_{4}$ on amorphous calcium phosphates [8]. It also yields an increased compression strength and Young's modulus after sintering compared to nonmicrowave irradiation [9]. Hydroxyapatite and biphasic calcium phosphate were observed to have twice the compressive strength and a greater elastic modulus. The use of microwave irradiation has been used to develop calcium phosphates, but not as a method for purposefully creating porosity during synthesis of a pure TCP material $[8,9]$. 
Medical devices and therapies aim to alter and improve a part of the body that is not properly functioning. Orthopedic implants made of metallic alloys are subject to corrosion, which reduces the mechanical properties of the implant and can cause future surgeries to replace the implant [3]. Metallic alloys can also release ions that interact with ions in the bloodstream which can have toxic effects [10].

The goal of this project was to synthesize tricalcium phosphate with bone-like properties using the microwave energy. In order to accomplish this goal, there are three specific objectives. The first was to experimentally demonstrate that combustion synthesis can be induced through microwave energy. The second was to examine the thermal behavior of this new volumetric combustion synthesis approach and characterize physical properties of the product. The third was to engineer functionally graded structures. 


\section{CHAPTER II}

\section{MATERIALS AND METHODS}

\section{Materials}

\section{Reactants}

Three reactants were used to form the final tricalcium phosphate product.

Calcium nitrate tetrahydrate, $\mathrm{Ca}_{3}(\mathrm{NO})_{4} \cdot 4 \mathrm{H}_{2} \mathrm{O}$, and ammonium phosphate dibasic, $\left(\mathrm{NH}_{4}\right)_{2} \mathrm{HPO}_{4}$, were the oxidizers and main reactants that form tricalcium phosphate. Urea, $\mathrm{CO}\left(\mathrm{NH}_{4}\right)_{2}$, was used as the fuel and as a space holder to add porosity in the structure. $\mathrm{Ca}_{3}(\mathrm{PO})_{4} \cdot 4 \mathrm{H}_{2} \mathrm{O}$ has a colorless, crystalline form with a molecular weight of $236.15 \mathrm{~g} / \mathrm{mol}\left(\mathrm{NH}_{4}\right)_{2} \mathrm{HPO}_{4}$ has a white, crystalline form with a molecular weight of $132.06 \mathrm{~g} / \mathrm{mol}$. $\mathrm{PCO}\left(\mathrm{NH}_{4}\right)_{2}$ was obtained in solid form and has a molecular weight of $60.06 \mathrm{~g} / \mathrm{mol}$. All reactants were purchased from Sigma Aldrich.

\section{Mixture-sample preparation}

The stoichiometric equation for the reactant is:

$3\left[\mathrm{Ca}\left(\mathrm{NO}_{3}\right)_{2} \cdot 4 \mathrm{H}_{2} \mathrm{O}\right]+2\left[\left(\mathrm{NH}_{4}\right)_{2} \mathrm{HPO}_{4}+\mathrm{CO}\left(\mathrm{NH}_{2}\right)_{2}\right] \rightarrow \mathrm{Ca}_{3}\left(\mathrm{PO}_{4}\right)_{2}+\left(27 \mathrm{H}_{2} 0+8 \mathrm{~N}_{2}+3 \mathrm{CO}_{2}\right)(1)$ Three different equivalence ratios, $\phi=1.0,1.5$, and 2.5 were prepared to examine the effect of increased urea concentration on final porosity [7]. 5 grams were weighed for each sample.

Reactants were poured into a beaker and mixed with a spatula. The mixture was then saturated in $5 \mathrm{~mL}$ of deionized water in separate beakers. The mixture was placed on a hot plate (IKA C-Mag) and heated at $150^{\circ} \mathrm{C}$ for about 50 minutes or until the mixture foamed. Once foaming occurred, the beaker was removed from the hot 
plate. The foam was then poured onto a 10.16 x $5.01 \mathrm{~cm}$ acrylic block because acrylic does not absorb microwave energy.

The same reactants were used for the second experiment. However, only two ratios were used $(\phi=1$ and $\phi=2.5) .1$ gram was weighed for each mixture, and it was saturated in $1 \mathrm{~mL}$ of deionized water in separate beakers. The mixtures were then placed simultaneously then placed on a hot plot (IKA C-Mag) and heated at $150^{\circ}$ until the mixture formed a foam (about 25 minutes). Once foaming occurred, the beaker was removed from the hot plate. A line was drawn on the acrylic block, with the left of the line labeled $\phi=1$ and the right labeled $\phi=2.5$.

\section{Microwave combustion synthesis}

Figure 2.1 illustrates the technique used to heat the samples with microwave irradiation and how to obtain microwave diagnostics. The microwave has an atmospheric temperature of $20^{\circ} \mathrm{C}$. The IR camera was set to image 1.5 frames/s. The acrylic block was placed in a WR 430 waveguide microwave, $1 \mathrm{~m}$ from the microwave source. The foam was then heated for 5 minutes at $2.45 \mathrm{GHz}$ ( 140 watts) in the first experiment and $2.6 \mathrm{GHz}(\sim 145$ watts $)$ in the second experiment. Transient thermal heating was recorded with FLIR Phoenix 9803 high speed IR camera.

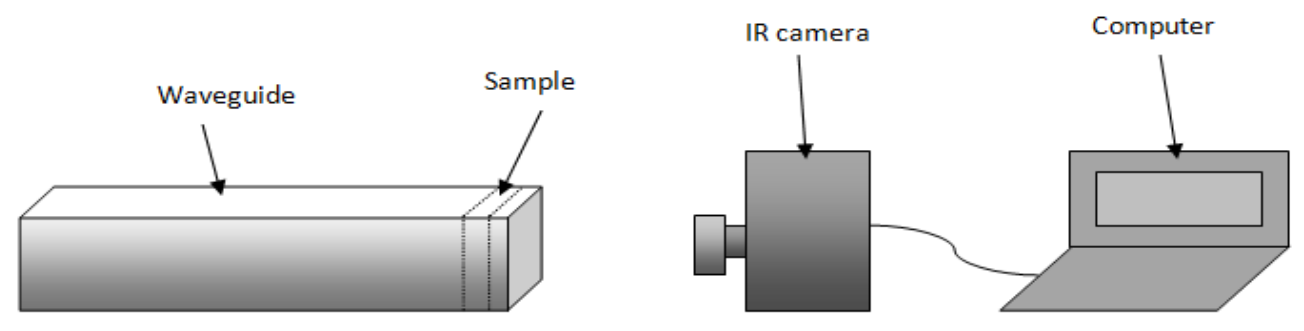

Figure 2.1 Schematic shows the IR camera capturing images of the sample to be analyzed on the FLIR ResearchIR software as a result of the electromagnetic wave in the WR430 waveguide. 


\section{Material characterization}

The acrylic block was removed and allowed to cool in an ambient environment. After cooling, cross sections were obtained from the sample using a razor blade.This sample was repeated for each composition. For the second experiment, sections were obtained from the left of the marker, the right of the marker, and in the area along the marked line in order to have a sample representative of each urea concentration.

Samples were mounted on sample holder using carbon tape. They were then coated with iridium using a Hummer V sputter coater. SEM images were obtained using a Hitachi 4300 at $5 \mathrm{kV}$. For FTIR analysis, samples were compacted to obtain IR spectra using Bruker Tensor 27 and data was collected with OPUS Spectroscopy software. 


\section{CHAPTER III}

\section{RESULTS AND DISCUSSION}

\section{Microwave combustion synthesis}

\section{Thermal analysis}

Figure 3.1 shows the temperature gradient heating rate over a five minute

period using $2.6 \mathrm{GHz}$, and that the overall rate of change is $10.46^{\circ} \mathrm{C} / \mathrm{s}$. The

combination of increasing the frequency from $2.45 \mathrm{GHz}$ to $2.6 \mathrm{GHz}$ and using smaller sample sizes $(1 \mathrm{~g})$ resulted in drastically higher temperatures. The overall temperature of the entire material exceeds $837^{\circ} \mathrm{C}$ for each of the three samples, and the average final temperature is $862^{\circ} \mathrm{C}$. At this temperature there is complete removal of urea, as urea fully decomposes at about $700^{\circ} \mathrm{C}[17]$.

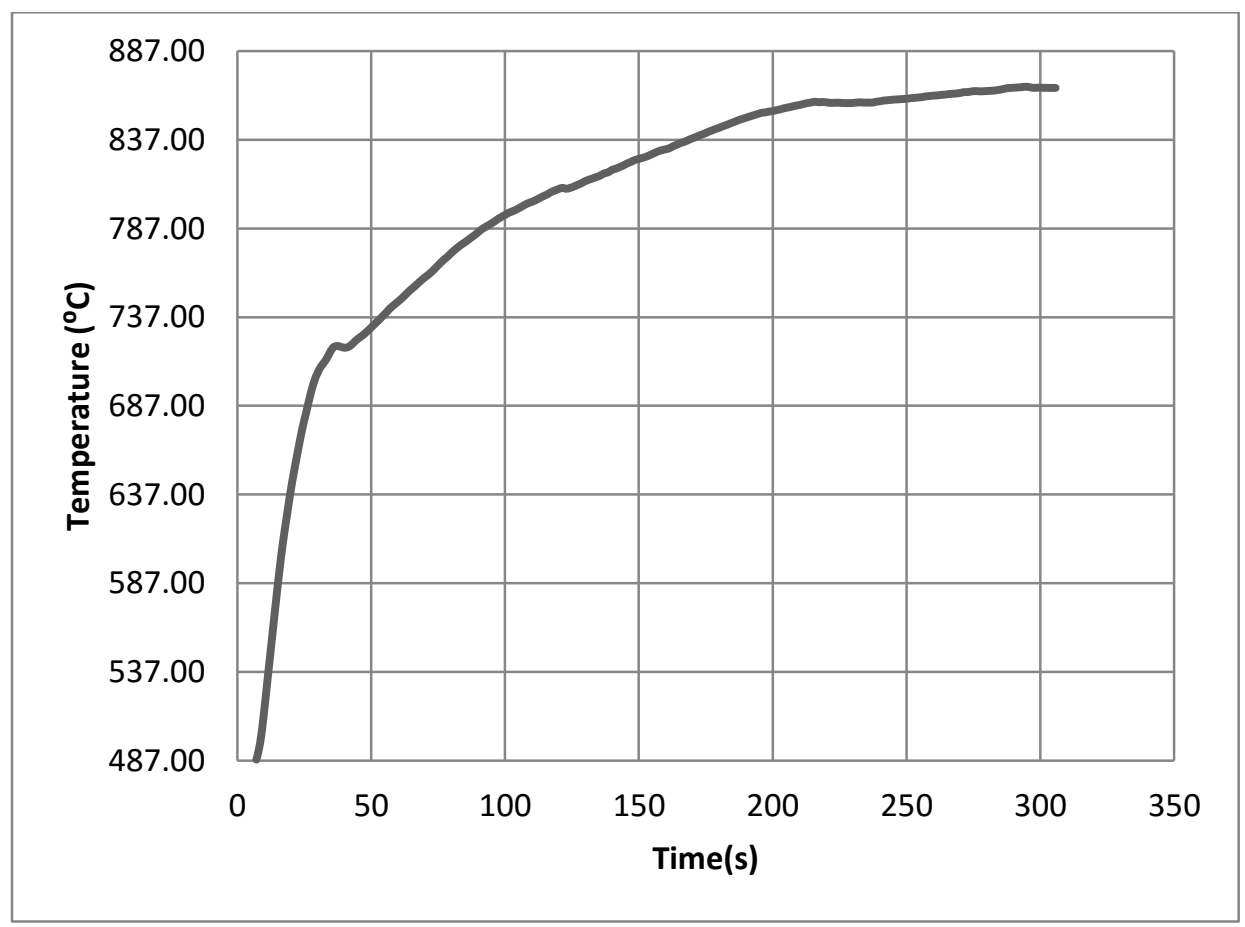

Figure 3.1 Average temperature change of material heated at $2.6 \mathrm{GHz}(140 \mathrm{~W})$ shows two different temperature trends as the reactant goes from semi-infinite solid to volumetric heating. 
There is a minimum value of $487^{\circ} \mathrm{C}$ in Figure 3.1 to compensate for limitations in the FLIR ResearchIR data collection software. This software cannot record the full range of temperatures, such that this minimum value was estimated to focus on the maximum temperature and a more conclusive representative of the temperature gradient. However, based on the trend in the first thirty seconds of Figure 3.1, the assumption that the material experienced a sharp rise to $487^{\circ} \mathrm{C}$ is reasonable.

There is a slight drop in the temperature from 38 to 40 seconds. All samples experienced a brief temperature decrease between 30 and 60 seconds. One sample had a sharp decrease and increase at 60 seconds. These deviations in temperature are likely due to shifting of the reactant material that occurs in the first minute of the microwave synthesis process. Figure 3.2a shows the electromagnetic wave output at 19 seconds. At 59 seconds (Figure 3.2b), there is a noticeable shift to the left. The liquid form of the sample causes movement, but as the time increase water is absorbed.

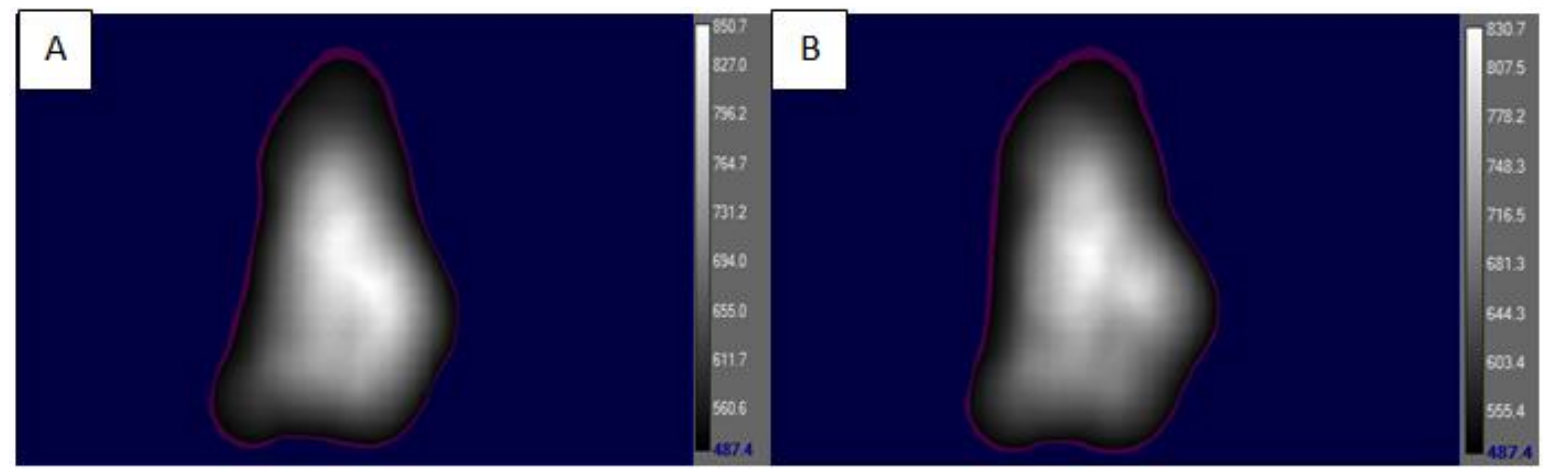

Figure 3.2 Graphical output shows the electromagnetic wave at (a) 29 seconds and (b) 59 seconds in the WR430 wavequide. Movement of the sample occurs in this time frame.

Figure 3.3 shows the transient average temperature in each sample ranged from 33 to $140^{\circ} \mathrm{C}$ when heated at $2.45 \mathrm{~Hz}$. The calculated reaction temperature is $33.85^{\circ} \mathrm{C}$. 
While reaction occurred in all materials, there are other reactants present based on FTIR results (Figure 3.4).

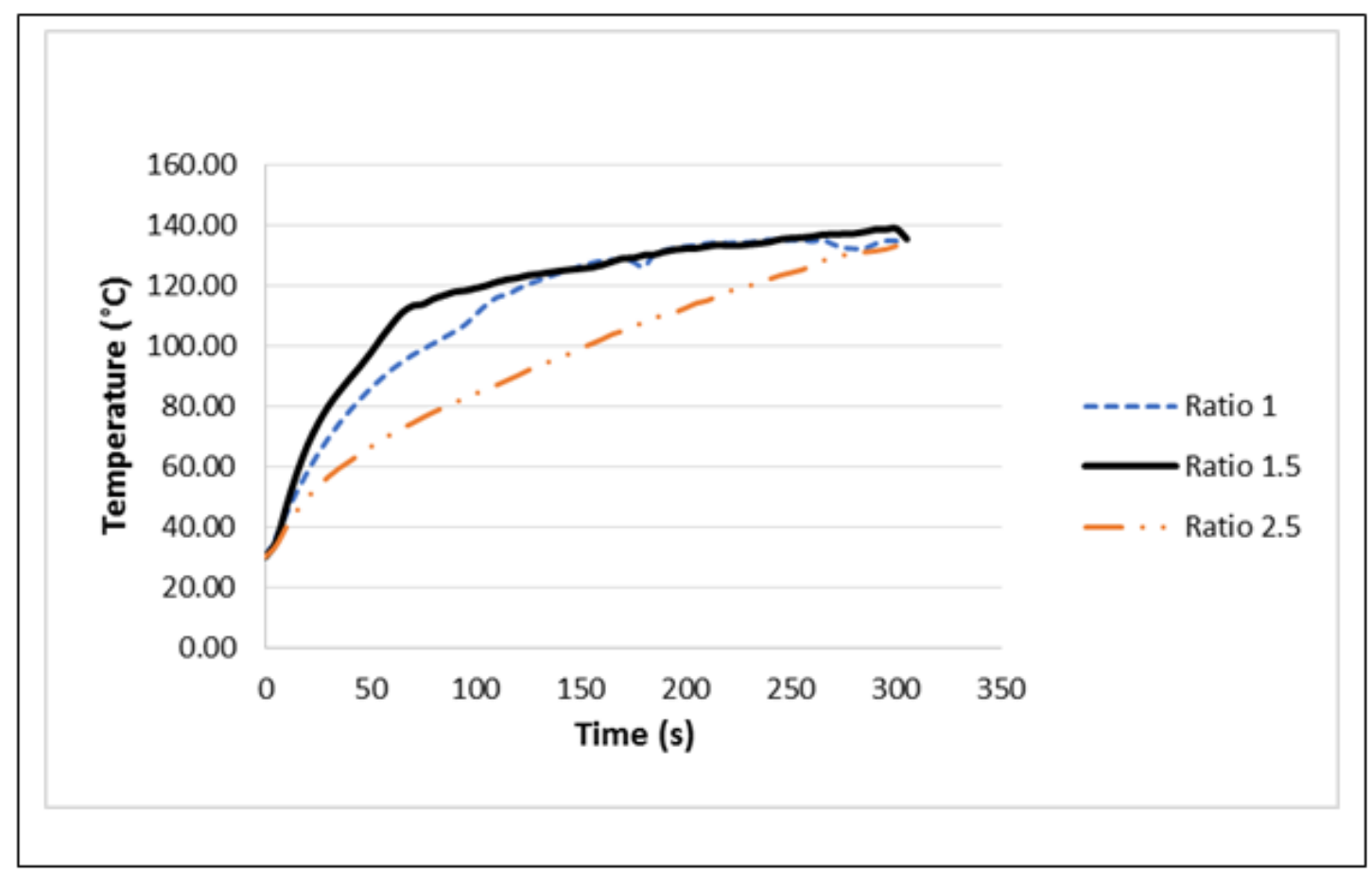

Figure 3.3 Average temperature change of material heated at $2.45 \mathrm{GHz}$ at 3 different equivalence ratios shows a more linear temperature gradient at $\phi=2.5$.

While $\phi=1$ and $\phi=1.5$ have a fairly similar temperature trend, $\phi=2.5$ is more

linear. The first two equivalence ratios contain less urea than $\phi=2.5$. The difference in this data could be due to the urea decomposition throughout the microwave synthesis process. Even though the samples are not heating at the same rate, they all reach within $5^{\circ} \mathrm{C}$ of each other in the final temperature $\left(\sim 135^{\circ} \mathrm{C}\right)$.

It is noted that TCP was formed through combustion synthesis triggered by volumetric microwave energy, but the desired temperatures (above $700^{\circ} \mathrm{C}$ ) were not reached. This is due the mass of the material. Using $5 \mathrm{~g}$ in each sample provided a thickness that caused a slow heating rate and low final temperature. Also, the 
microwave was set to $2.45 \mathrm{GHz}$. Increasing this setting to $2.6 \mathrm{GHz}$ increased the overall temperature the material is able to reach as well.

\section{FTIR analysis}

The FTIR results in Figures 3.4 and 3.5 show that the product species is

tricalcium phosphate (TCP) [11]. All of the tested equivalence ratios $(\phi=1,1.5,2.5)$ in Figure 5 follow the same trend and exhibit the same characteristic peaks. As the equivalence ratio increases, the corresponding transmittance also increases. The IR spectra of the functionally graded TCP in Figure 3.5 shows more distinct peaks at higher transmittance. These two variationsin percent transmittance are likely due to the increased concentration of the urea that did not fully decompose $\left(\mathrm{CH}_{4} \mathrm{~N}_{2} \mathrm{O}\right)$ in the samples depicted in Figure 5 [12]. The six major peaks in Figure 3.5 correspond with the previous values for the IR spectra evaluated at different urea concentrations. These peaks that take place at $3469,3228,1624,1340,1028$, and $812 \mathrm{~cm}^{-1}$ show the water, carbonate, and phosphate bands [12]. 


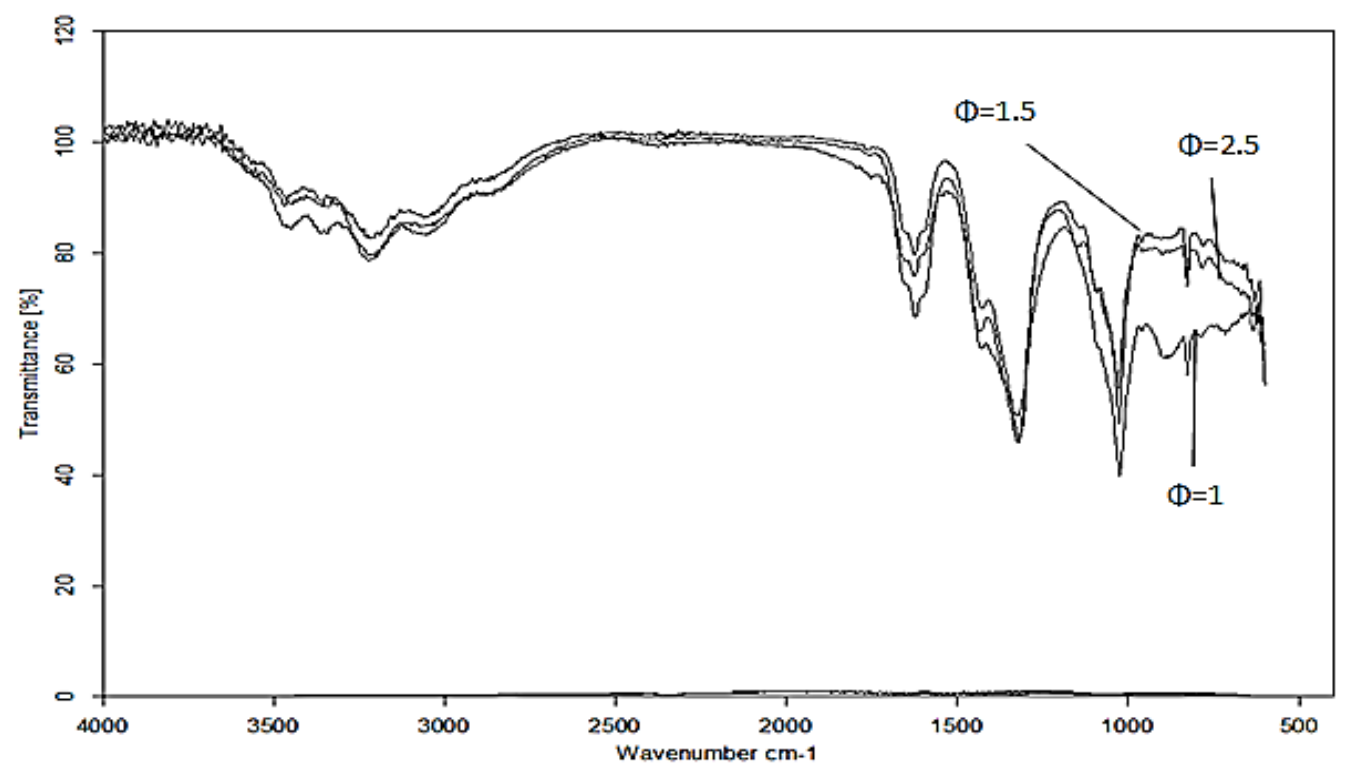

Figure 3.4 Transmittance as a function of wavenumber from FTIR analysis shows product species is tricalcium phosphate for sample heated at $2.45 \mathrm{GHz}$. Equivalence ratio of form indicated for each curve.

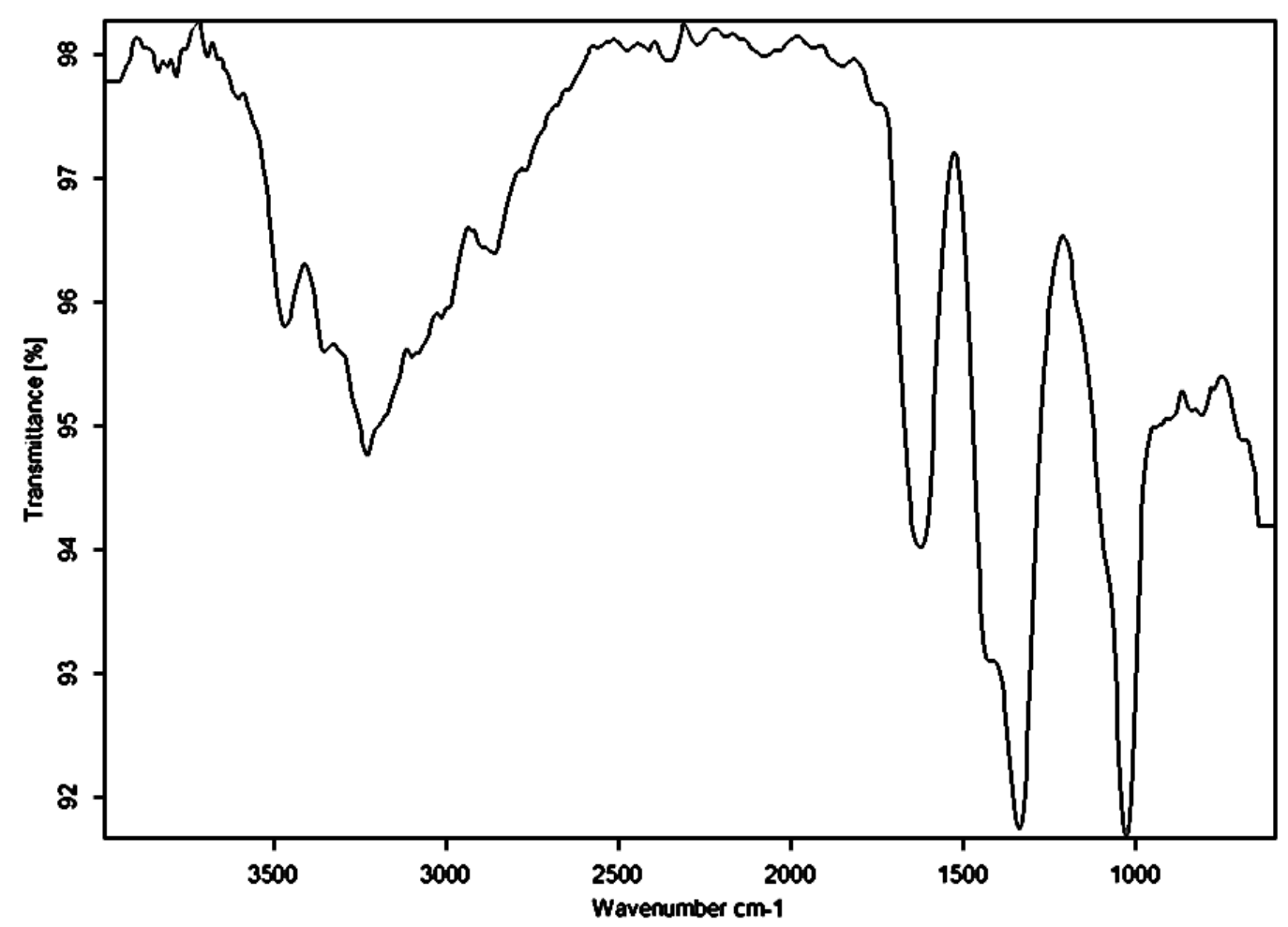

Figure 3.5 Transmittance as a function of wavenumber from FTIR analysis shows product species is tricalcium phosphate for sample heated at $2.6 \mathrm{GHz}$. 
At about $3500 \mathrm{~cm}^{-1}, 3300 \mathrm{~cm}^{-1}$, and $3200 \mathrm{~cm}^{-1}$, the adsorbed water bands can be seen in Figure 3.4 [13]. This hydroxyl ion stretching and water absorption results from the product's affinity for water. Calcium nitrate, a reactant in the chemical reaction, also absorbs water present in the air and surroundings. A calcium nitrate peak appear at $1800 \mathrm{~cm}^{-1}$ and disappears at about $600^{\circ} \mathrm{C}$, at which point the impurities formed during synthesis are removed [12].

At $1300 \mathrm{~cm}^{-1}$ and $1600 \mathrm{~cm}^{-1}$ there is a carbonate band [12]. At $700 \mathrm{~cm}^{-1}$ all carbonate ions begin to disappear from the crystalline structure and carbonate ions decompose [15]. Four visible phosphate bands are present: two strong bands at 800 $\mathrm{cm}^{-1}$ and $1000 \mathrm{~cm}^{-1}$ and two weak bands at about $575 \mathrm{~cm}^{-1}$ and $600 \mathrm{~cm}^{-1}$ [12]. These peaks show the decomposition of phosphate ions due to temperature change [14].

Also important to note is $\beta$-tricalcium phosphate at $950 \mathrm{~cm}^{-1}$ that undergoes a phase change to $\alpha-\mathrm{TCP}$ at $1200^{\circ} \mathrm{C}$ [16], and this transition is present throughout the IR spectrum at about $980 \mathrm{~cm}^{-1}$ and $1050 \mathrm{~cm}^{-1}$ [12]. Overall, the synthesized material exhibits IR spectra characteristic of TCP and some similar to hydroxyapatite [11].

\section{Semi-infinite solid}

The first 30 seconds of the microwave synthesis process exhibits thermal behavior different from the remainder of the process. This results in a sharp rise in temperature, followed by a slower temperature increase after about 30 seconds. Figure 3.6 shows a comparison between a local experimental region, an average, and a theoretical trend during the first 30 seconds. 


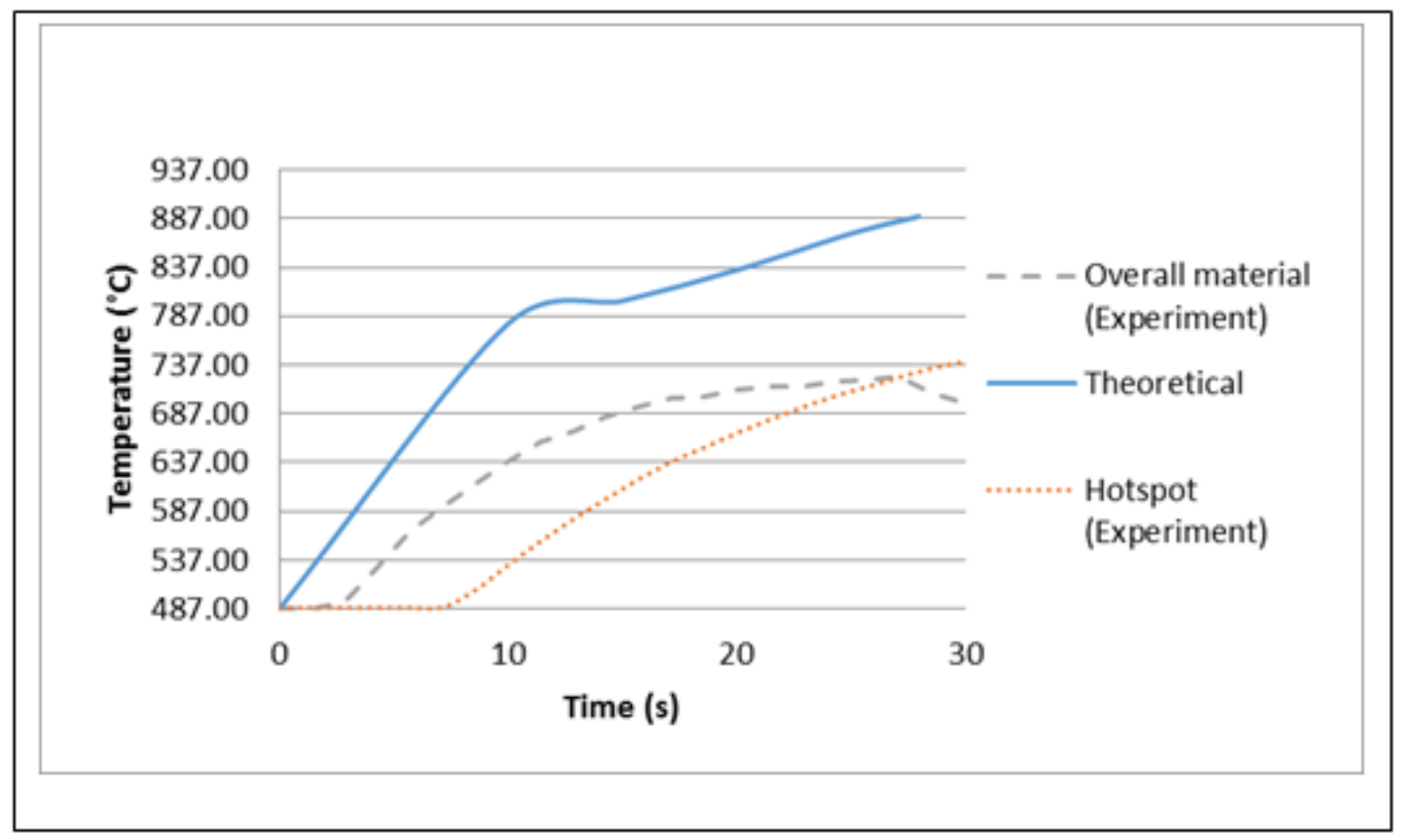

Figure 3.6 Graphical output during the first 30 seconds of microwave synthesis shows semi-infinite solid thermal behavior.

This theoretical trend was modeled as a semi-infinite solid in the early stage microwave synthesis. When temperature gradients are highest at the surface, the temperature increase follows a similar trend indicative of this assumption. This semiinfinite model was formulated using the constant surface heat flux boundary condition such that the Eq. (2) describes transient temperature distribution:

$$
T-T_{i}=\frac{2 q\left(\frac{\alpha t}{\pi}\right)^{\frac{1}{2}}}{k} \exp \left(\frac{-x^{2}}{4 \alpha t}\right)-\frac{q x}{k} \operatorname{erfc}\left(\frac{x}{2 \sqrt{\alpha t}}\right)[18]
$$

where $\mathrm{T}=$ temperature, $\mathrm{T}_{\mathrm{i}}=$ initial temperature, $\mathrm{k}($ conductivity $)=41 \times 10^{-4} \mathrm{~W} / \mathrm{m}-\mathrm{K}$ [19], $\alpha$ (diffusivity) $=5.7 \times 10^{-7} \mathrm{~m}^{2} / \mathrm{s}, \mathrm{x}=0.025 \mathrm{~m}$, and heat flux is $\mathrm{q}=50 \mathrm{~W} / \mathrm{m}^{2}$.

During the first 30 seconds, the rapid rise in temperature is localized near the surface. This is likely possible due to the loading direction of the reactant in the microwave wave guide. The radial surface of the material was placed perpendicular to 
the camera and axial length parallel to the electromagnetic waves. These effects are more drastic in the first 10 seconds. The microwave energy initially cause heating mostly at the surface of the material leaving the center of the material to remain at its original temperature [20]. As the heating then effects the remainder of the material, the reactant experiences a decrease in temperature rate.

The theoretical data is more consistent with the hot spot, then the overall material. This makes sense because the hot spot experienced increased temperature at a faster rate throughout the entire 5 minutes. The microwave energy was absorbed by the hot spots first, and the overall internal temperature of the material began to respond and increase at a later time. This delay in the plot shifts the experimental data to the right. However, it can still be seen that the trends are the same.

There is a brief decrease in Figure 3.6 at 28 seconds. This is a result of the material moving in the first 30 seconds. The reactant is a foam structure when placed in the microwave for synthesis. Its liquid nature likely caused it to shift slightly in the beginning. After that initial dip in temperature, the temperatures proceed to increase at a steady rate. It is also important to note that the orientation of the material and the acrylic block could have impacted this shift as well. Heating the reactant causes expansion and increased malleability. This was proven by using a lighter directly on the material to ensure to see how it would react. The foam material was heated, and movement of the foam was observed. Once the heat was removed, the material hardened and solidified. Upon repeated direct heat exposure from the lighter, the solid material once again began to expand. During the microwave experiment, it is possible 
that the microwave energy caused the material to slide down the acrylic block while still in the liquid state. Despite slight movement of the foam during heating, the entire material resulted in the formation of TCP.

\section{Lumped capacitance (volumetric)}

After the first 30 seconds in the microwave, the material began to exhibit a different thermal behavior. Figure 3.7 reveals a slower increase in temperature compared to the first 30 seconds.

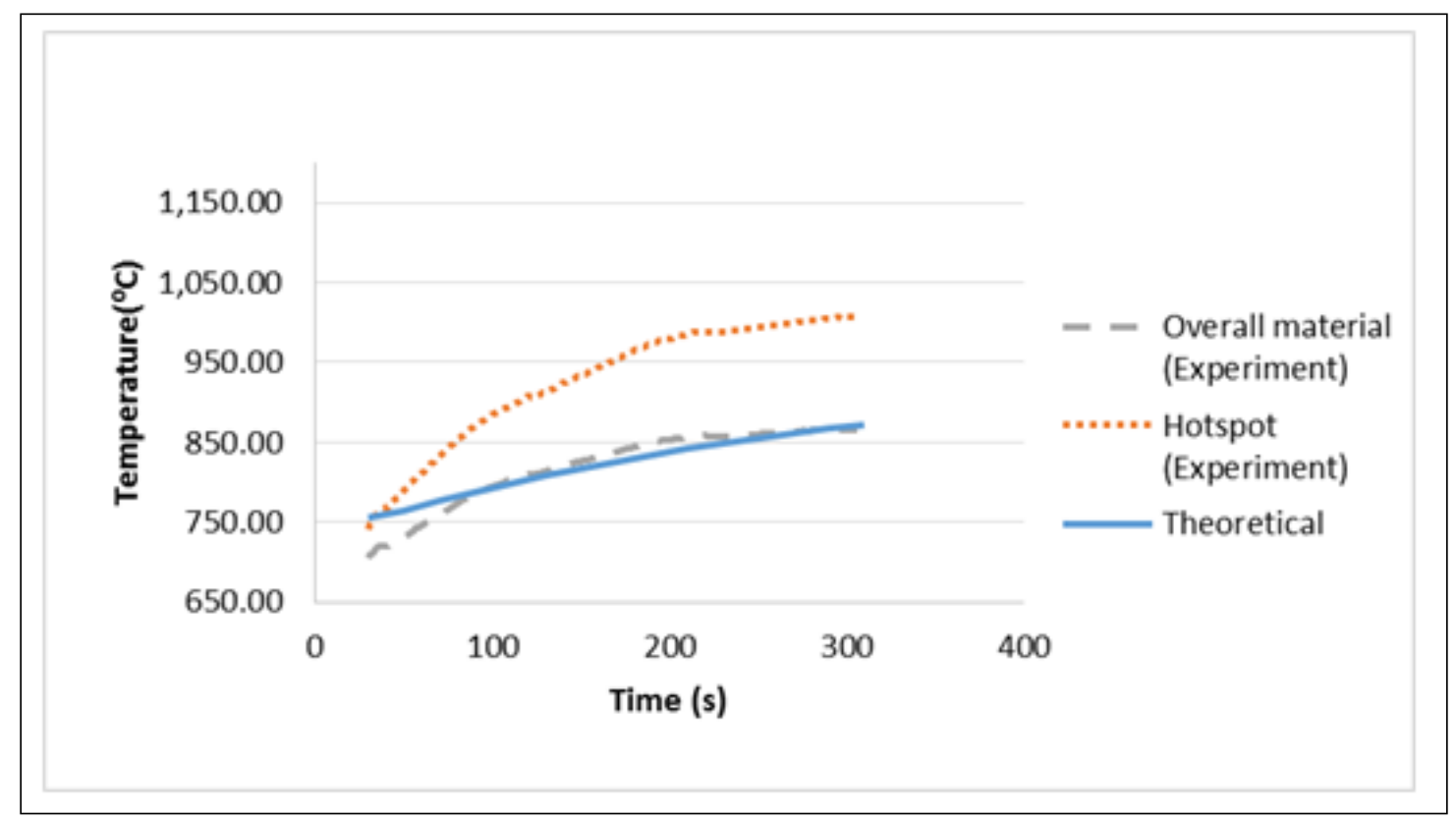

Figure 3.7 Graphical output after 30 seconds of microwave synthesis shows volumetric heating.

The overall heating rate experienced a decrease from $8.47^{\circ} \mathrm{C} / \mathrm{s}$ to $0.65^{\circ} \mathrm{C} / \mathrm{s}$. The hot spots decreased from $10.83^{\circ} \mathrm{C} / \mathrm{s}$ to $1.35^{\circ} \mathrm{C} / \mathrm{s}$. During the latter heating rates, the microwave energy has penetrated the entire material volumetrically. This caused more uniform heating throughout the remainder of the 5 minute heating time. Based on the shift change in the heating rate, the experimental data was once again compared to a 
mathematical simulation of transient conduction. At 30 seconds, the foam has a steadier heating rate. The spatially uniform temperature distribution is assumed for this material, and is modeled against the lumped capacitance model. This model assumes that there is a uniform temperature distribution throughout the material at any point in the microwave synthesis process (after 30 seconds). The lumped capacitance model is shown in Eq. (3):

$$
\frac{T-T_{\infty}}{T_{i}-T_{\infty}}=\exp \left[-\left(\frac{h A}{\rho V c}\right) t\right]
$$

where $T_{\infty}$ (temperature of environment $)=20^{\circ} \mathrm{C}, \mathrm{h}$ (heat transfer coefficient $)=6 \times 10^{-}$ ${ }^{4} \mathrm{~W} / \mathrm{m}^{2}-\mathrm{K}, \rho$ (density) $=3240 \mathrm{~kg} / \mathrm{m}^{3}$, and area is $\mathrm{A}=141 \mathrm{~cm}^{2}$.

While the semi-infinite solid model was more indicative of the hot spots behavior during the first 30 seconds, Figure 3.7 shows that the lumped capacitance simulation is closer to the overall material. However, due the previous spike in temperature, it will always have a high temperature the rest of the material. Even though the microwave did not yield results exactly like the capacitance model, the TCP material still behaviors like a lumped solid. This was verified by the Biot number calculated to be 0.02 using Eq. (4):

$$
B i=\frac{h L}{k}[18]
$$

It should also be mentioned that one of the samples was not able to complete the full 5 minutes in the microwave. The hot spot of that sample continued to increase very rapidly, even though the heating rate was lower than in the first 30 seconds. The hot spot reached $1200.3^{\circ} \mathrm{C}$. At $1200^{\circ} \mathrm{C}$ a new phase of TCP is formed, $\alpha$-TCP [16]. This is not dangerous or detrimental for the purposes of the experiment, but the 
machine was stopped at 200 seconds to maintain consistency throughout the samples. The temperature throughout the rest of the sample remained under $1200{ }^{\circ} \mathrm{C}$.

The rapid increase in the first 200 seconds of one sample could be attributed to thermal runaway. Thermal runaway is a phenomena that causes ceramics to increase temperature at a high rate toward its melting point as result of the high power levels in the microwave [21]. Early removal of the sample may have prevent melting and decomposition of the sample. Power was subsequently reduced from $25 \%$ to $20 \%$ for the remaining samples. There were no further instances of thermal runaway in the remaining samples.

\section{Elemental analysis}

Figure 3.8 and Table 3.1 show the EDS results of the product material. The elemental analysis shows that the combustion synthesis resulted in tricalcium

phosphate, $\mathrm{Ca}_{3}\left(\mathrm{PO}_{4}\right)_{2}$. Carbon and nitrogen are both present in the EDS spectra, with a weight percent of 10.23 and 9.23 respectively.

Table 3.1 EDS illustrates the highest weight percent of the product is composed of oxygen, phosphorus, and calcium.

\begin{tabular}{c|l} 
ELEMENT & WT. \% \\
\hline C K & 10.23 \\
N K & 09.07 \\
O K & 33.59 \\
P K & 27.84 \\
CA K & 19.27
\end{tabular}




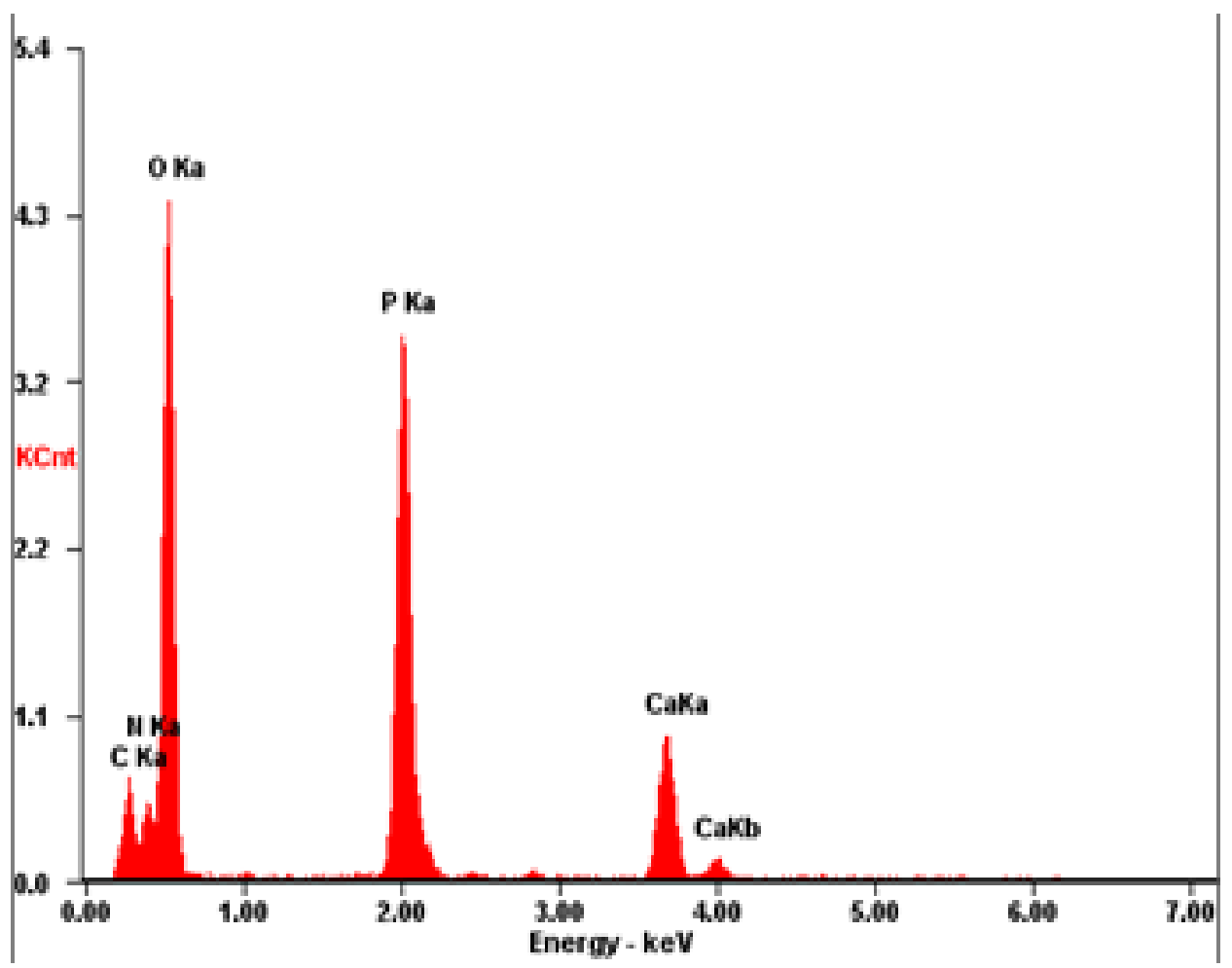

Figure 3.8 Energy Dispersive Spectrometry (EDS) illustrates the resulting product species is tricalcium phosphate.

Based on the FTIR results discussed in Figure 3.5, carbon still present in the structure is possible in the form of carbonate ions. Carbonate ions are not detrimental in this TCP product because carbonate ions are found in human bone [22]. It is more likely, however, that the elemental carbon may show up in the EDS data as a result of the carbon tape used to hold the sample in the place. There could be several reasons for nitrogen still present in the product. Nitrogen may not have been fully removed during the combustion synthesis. Nitrogen is used in some medical devices, and will not affect the TCP functioning [23]. Nitrogen gas is used in electron microscopy process as a vacuum to absorb moisture from the product for analysis. Therefore, it is not unfounded that the EDS would be sensitive to the chemistry within the EDS 
chamber. All elements present in the EDS data are with components of TCP or elements used to obtain the EDS results.

\section{Functionally graded porosity}

Scanning electron microscopy (SEM) depicts the porosity of the three different equivalence ratios $(\phi=1, \phi=1.5, \phi=2.5)$ in Figure 3.9. The images were recorded at different scales to magnify the clear difference in porosity based on the amount of urea present in the material. Magnification was enhanced until pores were visible.

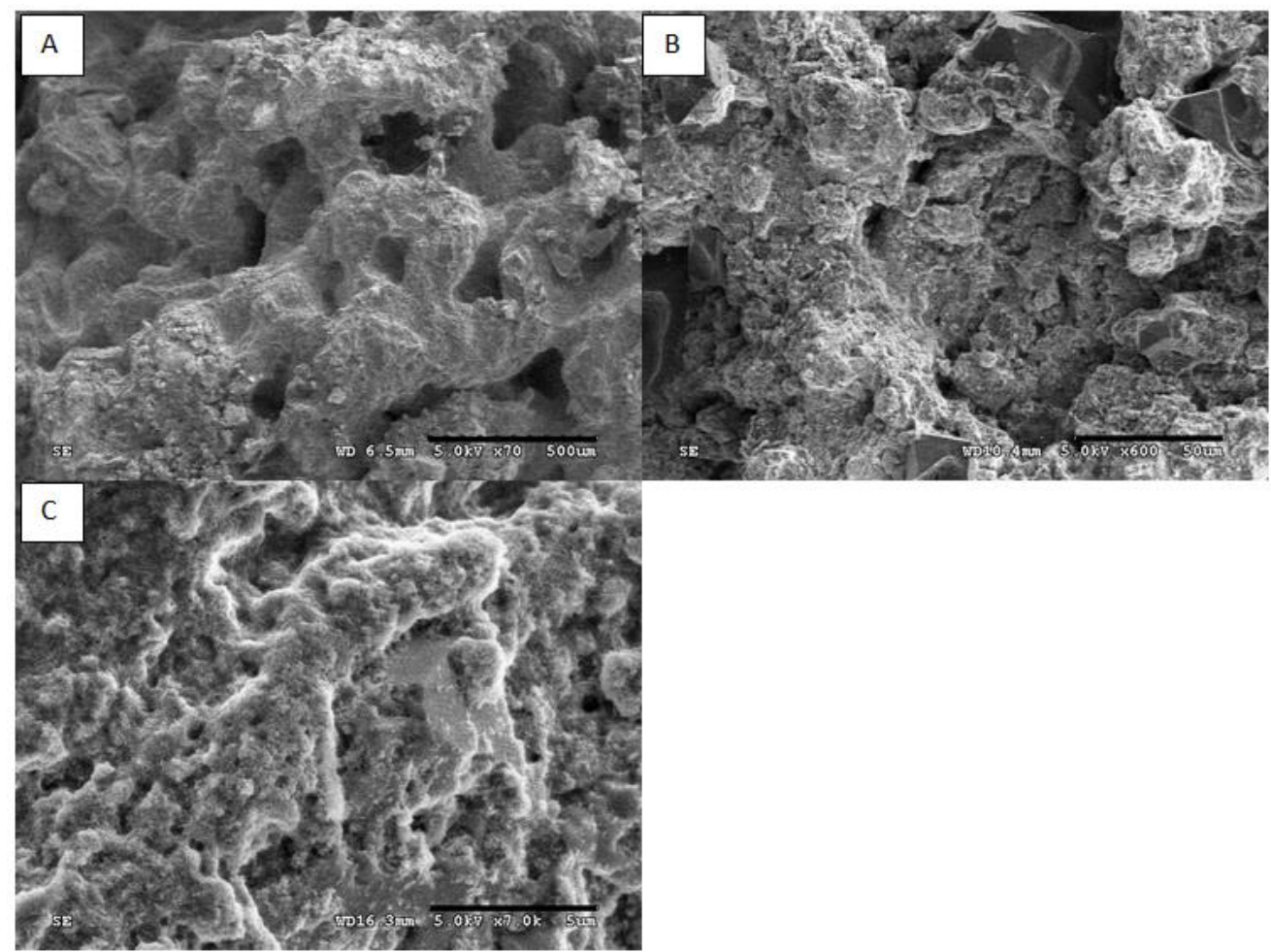

Figure 3.9 Scanning Electron Microscopy micrographs with varied resolution as indicated for 3 different equivalence ratios, (a) $\phi=2.5$, (b) $\phi=1.5$, (c) $\phi=1$, indicating increasing pore structure with increasing equivalence ratio.

Porosity calculations confirm that the increase in urea concentration leads to an increase in overall pore size. The large porosity difference between the smallest and largest equivalence ratios $(\phi=1$ and $\phi=2.5)$ lead to the subsequent experiment that 
tested only those two ratios in order to observe the difference in porosity if both samples were incorporated in one sample.

Samples were then taken from each of the two equivalence ratios $(\phi=1, \phi=2.5)$ as well as from a section in the middle of the graded TCP product. This middle section is composed of both ratios. Figure $3.10 \mathrm{a}$ shows a mean pore area of $0.0026 \mu \mathrm{m}^{2}$. There are larger pores as well, but the majority of the pores are smaller than Figure 10b and Figure 3.10c. In the $\phi=2.5$ sample, the pore sizes are noticeably larger. The sample containing both ratios has both small pores and large pores. There is a clear gradient in the pore size from the left to right at this sample. The visible distinction of the different ratios in this image, illustrate the impact of urea on porosity.

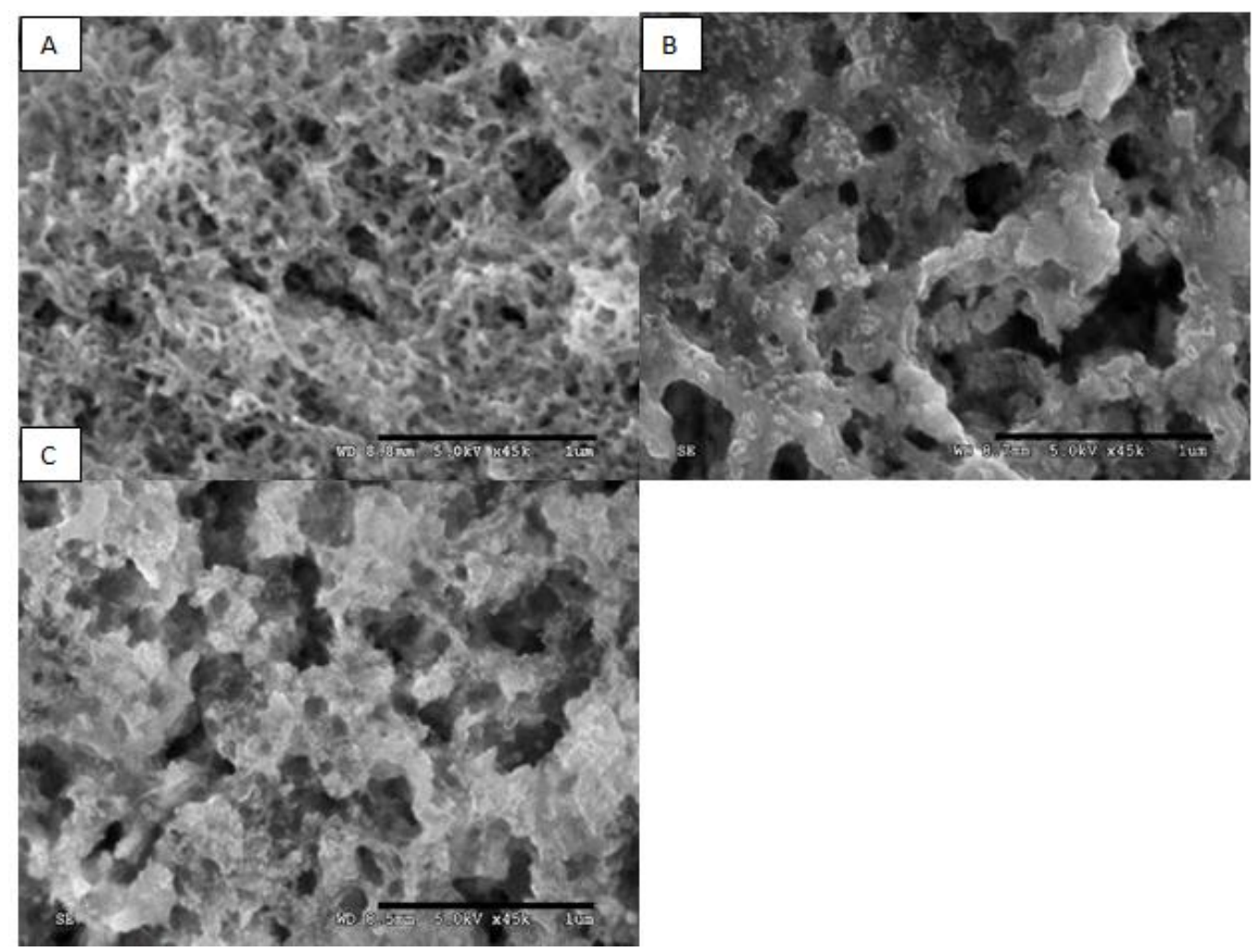

Figure 3.10 Scanning Electron Microscopy micrographs at as indicated for 3 different equivalence ratios, (a) $\phi=1$, (b) $\phi=1 / 2.5$ (mixed), (c) $\phi=2.5$, indicating increasing pore structure with increasing equivalence ratio. 
Porosity data obtained by ImageJ (and DiameterJ) validates the SEM results that the pore size increases with increasing urea concentration (Table 3.2). The small urea to calcium phosphate ratio contains more pores than all of the samples, but these pores are very small. The maximum pore area is $0.0852 \mu \mathrm{m}^{2}$. The larger ratios have larger pores that range from $0.0002-0.235 \mu \mathrm{m}^{2}$ that compensates for the lack of actual pore numbers. The sample containing a mixture of both ratios had the highest percent porosity.

Table 3.2 Porosity analysis from ImageJ shows the increase in mean pore size as a result of increased urea concentration as indicated by the 3 equivalence ratios evaluated.

\begin{tabular}{|c|c|c|c|c|c|}
\hline & $\begin{array}{l}\text { Mean Pore } \\
\text { Area }\left(\boldsymbol{\mu m}^{2}\right)\end{array}$ & $\begin{array}{l}\text { Min. Pore } \\
\text { Area }\left(\boldsymbol{\mu m}^{2}\right)\end{array}$ & $\begin{array}{l}\text { Max. Pore } \\
\text { Area }\left(\boldsymbol{\mu m}^{2}\right)\end{array}$ & $\begin{array}{l}\text { Percent } \\
\text { Porosity }\end{array}$ & \# of Pores \\
\hline$\Phi=1$ & 0.0098 & 0.0002 & 0.0852 & 0.1484 & 78 \\
\hline $\begin{array}{l}\Phi=\text { mixed } \\
\text { (middle) }\end{array}$ & 0.013 & 0.0002 & 0.0710 & 0.6955 & 43 \\
\hline$\Phi=2.5$ & 0.0218 & 0.0002 & 0.2352 & 0.3387 & 40.5 \\
\hline
\end{tabular}

The combination of 2 different ratios caused the sample to contain both a high quantity of small pores in one area and a low number of large pores in another area. There is also a very large pore in the $\phi=2.5$ region that contributed to the high porosity of this sample. Several samples were imaged for each ratio, and Table 2 depicts the average of all samples. These results show that urea is sufficient to manipulate porosity of TCP and that a solid structure can be obtained with varied porosity. 


\section{CHAPTER IV}

\section{CONCLUSION}

Tricalcium phosphate in the beta phase was synthesized using microwave synthesis. Urea concentration altered the porosity of the final product after microwave synthesis. Microwave irradiation was successful in providing uniform heating of tricalcium phosphate. This volumetric heating technique synthesized a functionally graded structure with controlled porosity. Pore size ranged from 0.0098 to $0.235 \mu \mathrm{m}$, with the area of the product with the highest urea in the reactant having the highest pore sizes.

The synthesized tricalcium phosphate doesnot contain the porosity of human bone, but the porosity gradients provide voids that are beneficial to accommodatedifferent bone formation and resorption rates. Microwave synthesis can be used to synthesize commercial tricalcium phosphate for various bone defects while taking into account the difference in bone microstructure. This technology can ultimately transform the way bioceramics like tricalcium phosphate (and other calcium phosphates) can be made to exhibit more properties that are like human bone. 


\section{BIBLIOGRAPHY}

[1] Kolk, A., Handschel, J., Drescher, W., Rothamel, D., Kloss, F., Blessmann, M., et al. (2012). Current trnds and future perspectives of bone substitute materials -

From spaceholders to innovative biomaterials. 40 .

[2] Paital, S. R., \& Dahotre, N. B. (2009). Calcium phosphate coatings for bio-implant applications: Materials, performance, factors, and methodologies. 66.

[3] Barrere, F., van Blitterswijk, C. A., \& de Groot, K. (2006). Bone regeneration: molecular and cellular interactions with calcium phosphate ceramics. 1 (3).

[4] Chug, A., Shukla, S., Mahesh, L., \& Jadwani, S. (2013). OsseointegrationMolecular events at the bone-interface:A review. 25.

[5] Vollmer, N., King, K., \& Ayers, R. (2015). Biological potential of calcium phosphate biopowders produced via decomposition combustion synthesis. 41.

[6] Volkmer, T., Lengler, F., Barreiro, O., Sousa, V., \& dos Santos, L. (2013). Novel method for the obtainment of nanostructured calcium phosphate cements: Synthesis, mechanical strength and cytotoxicity. 235.

[7] Vollmer, N., \& Ayers, R. (2012). Decomposition Combustion Synthesis of Calcium Phosphate Powders for Bone tissue Engineering. 21.

[8] Zhou, H., \& Bhaduri, S. (2011). Novel microwave synthesis of amorphous calcium phosphate nanosphere.

[9] Pasand, E. G., Nemati, A., Solati-Hashjin, M., Arzani, K., \& Farzadi, A. (2012). Microwave assisted synthesis properties of nano HA-TCP biphasic calcium phosphate. 19 (5).

[10] B. Feddes, P. Gonzalez, J. Serra, J. Pou, S. Chiussi, J. G. Wolke and C. Jager, " Characterization of Thin Film Phosphate Coating," in Thin Film Phosphate Coatings for Medical Implants, Springer Media, 209, pp. 25-66.

[11] B. Ratner, A. Hoffman and F. Schoen, Biomaterials Scienc. An Introduction to Materials, Second Edition, Acsdemic Press, 2004.

[12] L. Berzina-Cimdina and N. Borodajenko, "Research of Calcium Phosphates Using Fourier Transform Infrared Spectroscopy," in Infrared Spectroscopy Materials Science, Engineering and, InTech, 2012.

[13] B. Leon and John A. Jansen, "Characterization of Thin Film Phosphate Coating," in Thin Film Phosphate Coatings for Medical Implants, Springer Media, 209, pp. 25-66.

[14] I. Rehman and W. Bonfield, "Characterization of hydroxyapatite and carbonated apatite by photoacoustic FTIR spectroscopy," Joirn of Materials Science: Materials in Medicine, vol. 8, no. 4, 1997.

[15] S. Meejoo, W. Maneeprakorn and P. Winotai, "Phase and thermal stability of nanocrystalline hydroxyapatite," Thermochimica Acta, pp. 115-120, 206.

[16] H.-S. Ryu, H.-J. Youn, K. S. Hong and B.-S. Chang, "An improvement in sintering property of b-tricalcium phosphate," Biomaterial, vol. 23, pp. 909-914, 2002. 
[17] P. M. Schaber, J. Colson, S. Higgins and D. Thielen, "Thermal decomposition (pyrolysis) of urea in an open reaction vessel," Thermochimica Acta, no. 424, pp. 131-142, 2004.

[18] F. P. Incropera, Fundamentals of Heat and Mass Transfer, Wiley, 2006.

[19] A. C. Bento, D. P. Almond, S. R. Brown and I. G. Turner, "Thermal and optical characterization of the calcium phosphate biomaterial," Journal of Applied Physics, vol. 79, no. 6848, 1996.

[20] S. Chaudhry and M. Zubair, "Heat conduction in a semi-infinite solid subject to time-dependent," Wirmeund Stoffibertragung, vol. 28, pp. 356-364, 1193.

[21] G. A. Kriegsmann, "Thermal runaway in microwave heated ceramics: A onedimensional model," Journal of Applied Physics, vol. 71, 1992.

[22] S. Jalota, A. Cuynet Tas and S. B. Bhaduri, "Microwave-assisted synthesis of calcium," Journal of Materials Research, vol. 19, no. 6.

[23] D. Garrett, A. Saunders, C. McGowan, J. Specks, K. Ganesan, H. Meffin, R. Williams and D. Nayagam, "In vivo biocompatibility of boron doped and nitrogen included conductive-diamond for use in medical implants.," Journal of Biomedical Materials Research Part B: Applied Biomaterials, vol. 104, no. 1, pp. 19-26, 2015. 